\title{
Research on Safety Risk Management of Railway Crossing Based on Fuzzy Set Theory
}

\author{
Lihua Shao ${ }^{a, *}$, Yu Zhao ${ }^{b}$ \\ School of Traffic and Transportation, Beijing Jiaotong University, Beijing, 100044, China \\ a15120866@bjtu.edu.cn, byuzhao@bjtu.edu.cn
}

Keywords: The Railway Crossing; Safety Risk Management; Fuzzy Set Theory.

\begin{abstract}
The railway crossing is the place where the railway and the road cross over the same plane, its security level not only affects the safety of railway traffic, but also affects the city's internal highway and pedestrian safety. Taking the Yellow River Road in Dalian as an Example, Safety risk assessment of railway crossing safety from four aspects: equipment factor, vehicle factor, crossing characteristic factor and management factor, according to the analysis results, the corresponding accident prevention measures should be put forward to improve the safety of the railway crossing and reduce the number of accidents and the losses caused.
\end{abstract}

\section{Summary of Safety Risk Management of Railway Crossing}

With the continuous development of the railway, the train running speed and running density continues to improve, the safety requirements of the railway crossing is also getting higher. There are many factors involved in the safety risk assessment of railway crossing, such as the failure of motor vehicle drivers and railway crossing guards, the failure of various equipment of crossing, the condition of crossing. Risk management is a high-level comprehensive management work, through the identification of risk, assessment and evaluation, in order to make the appropriate response. The application of safety risk management evaluation to the safety evaluation of railway crossing can effectively improve the safety level of railway crossing and prevent the occurrence of crossing accident, thus reducing the loss caused by the accident.

\section{Construction of Safety Risk Management Evaluation Model}

\subsection{Quantitative Analysis of Factors Affecting Railway Crossing Safety}

From the perspective of safety risk management, the whole factors that affect the railway crossing are divided into four aspects: equipment factors, vehicle factors, crossing characteristics and personnel factors.

Table 1.Factors Affecting Railway Crossing Safety

\begin{tabular}{|c|c|c|}
\hline Target layer & Index layer 1 & Index layer 2 \\
\hline \multirow{12}{*}{ Safety conditions of railway crossing } & \multirow{4}{*}{ equipment factors } & Signal safety status \\
\hline & & Crossing position setting situation \\
\hline & & Column wood safe state \\
\hline & & Crossing the train close to early warning time \\
\hline & \multirow{2}{*}{ vehicle factors } & Crossing the state of motor vehicles \\
\hline & & Crossing the vehicle density \\
\hline & \multirow{4}{*}{ crossing characteristics } & Crossing width \\
\hline & & Crossing slope \\
\hline & & Crossing the road and the railway angle \\
\hline & & Crossing the road near the road \\
\hline & \multirow{2}{*}{ personnel factors } & The condition of crossing guardians \\
\hline & & Ports security management file status \\
\hline
\end{tabular}

Classify the safety level of each indicator that affects the safety of the railway crossing, and take the combination of field investigation and expert scoring to determine the final score. Of which 100 
to 80 is divided into safety, 80 to 60 is divided into safer, 60 to 40 divided into general, 40 to 20 is more dangerous, 20 to 0 for the danger.

\subsection{Evaluation Model and Method of Variable Fuzzy Set}

It is known that the $\mathrm{m}$ indicator vector of the evaluation object is $X=\left(x_{1}, x_{2} \ldots x_{m}\right)$

According to $\mathrm{m}$ indicators of the $\mathrm{c}$ level of the standard interval matrix:

$$
Y=\left(\begin{array}{cccc}
{[a, b]_{11}} & {[a, b]_{12}} & \cdots & {[a, b]_{1 c}} \\
{[a, b]_{21}} & {[a, b]_{22}} & \cdots & {[a, b]_{2 c}} \\
\vdots & \vdots & & \vdots \\
{[a, b]_{m 1}} & {[a, b]_{m 2}} & \cdots & {[a, b]_{m c}}
\end{array}\right)
$$

To conduct a comprehensive evaluation. For the bigger the more excellent indicators, $a>b$, for the smaller the more excellent indicators $a<b$. The former is a decreasing indicator, the latter is an incremental index where.

$M_{i h}$ is the indicator $\mathrm{i}$ in the interval $[a, b]_{i h}$ on the relative membership degree of 1 point value, the general model for:

$$
M_{i h}=\frac{c-h}{c-1} a_{i h}+\frac{h-1}{c-1} b_{i h},
$$

The uniform model of the level h relative membership formula is:

When it falls on the left side and on the right side of the value:

$$
\begin{array}{cccc}
\mu_{A}\left(x_{i}\right)_{h}=0.5\left[1+\left(\frac{x_{i}-a_{i h}}{M_{i h}-a_{i h}}\right)^{\beta}\right] & x_{i} \in\left[a_{i h}, M_{i h}\right] & \mu_{A}\left(x_{i}\right)_{h}=0.5\left[1+\left(\frac{x_{i}-b_{i h}}{M_{i h}-b_{i h}}\right)^{\beta}\right] & x_{i} \in\left[M_{i h}, b_{i h}\right] \\
\mu_{A}\left(x_{i}\right)_{h}=0.5\left[1-\left(\frac{x_{i}-a_{i h}}{c_{i h}-a_{i h}}\right)^{\beta}\right] & x_{i} \in\left[c_{i h}, a_{i h}\right] & \mu_{A}\left(x_{i}\right)_{h}=0.5\left[1-\left(\frac{x_{i}-b_{i h}}{d_{i h}-b_{i h}}\right)^{\beta}\right] & x_{i} \in\left[b_{i h}, d_{i h}\right]
\end{array}
$$

The relative membership of the sample $\mathrm{j}$ to the level $\mathrm{h}$ is calculated from the following formula:

$$
{ }_{j} u_{h}{ }^{\prime}=\left\{1+\left[\frac{\sum_{i=1}^{m}\left[\omega_{i}\left(1-\mu_{A}\left(x_{i j}\right)_{h}\right)\right]^{p}}{\sum_{i=1}^{m}\left[\omega_{i} \mu_{A}\left(x_{i j}\right)_{h}\right]^{p}}\right\}^{\frac{\alpha}{p}}\right\}^{-1}
$$

Among them, $\omega_{i}$ is index weight; $\alpha$ is model optimization criteria parameters; $m$ is identify the index factor; $p$ is distance parameter, $p=1$ is haiming distance; $p=2$ is oushi distance. $\alpha, p$ called variable fuzzy model parameters, there are usually four combinations: (1) $\alpha=1, p=1$; (2) $\alpha=1, p=2$; (3) $\alpha=2, p=1$; (4) $\alpha=2, p=2$.

According to the four different combinations of parameters, we can get a corresponding nonnormalized synthetic relative membership matrix ${ }_{j} U_{h}^{\prime}=\left({ }_{j} u_{h}^{\prime}\right)$, Normalize it to get the normalized relative membership degree matrix of sample $\mathrm{j}$ to level $\mathrm{h}:{ }_{j} U_{h}=\left({ }_{j} u_{h}\right)$

Apply the level eigenvalue formula to calculate the level attribute $H=(1,2, \cdots c) \cdot{ }_{j} U_{h}$

And based on the criteria:

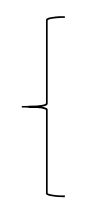

$$
\begin{aligned}
& 1.0 \leq \mathrm{H} \leq 1.5 \text {, belong to } 1 \text { rank } \\
& \mathrm{h}-0.5<\mathrm{H} \leq \mathrm{h} \text {, belong to } \mathrm{h} \text { rank, trend }(\mathrm{h}-1) \text { rank }(\mathrm{h}=2,3, \ldots, \mathrm{c}-1) \\
& \mathrm{h}<\mathrm{H} \leq \mathrm{h}+0.5 \text {, belong to } \mathrm{h} \text { rank, trend( } \mathrm{h}+1) \text { rank }(\mathrm{h}=2,3, \ldots,(\mathrm{c}-1)) \\
& \mathrm{c}-0.5<\mathrm{H}<\mathrm{c} \text {, belong } \mathrm{c} \text { rank }
\end{aligned}
$$

The samples were evaluated synthetically.

\subsection{The Calculation Steps}

1) Establish the safety evaluation index system of railway crossing, and classify the evaluation index according to the established level; 
2) According to the data obtained from the survey, the index eigenvalue $X$ matrix of each index of railway crossing is determined, and the $M_{i h}$ matrix is obtained according to the index standard interval matrix.

3) Determine the relative membership degree ${ }_{j} U=\left(\mu_{A}\left(x_{i j}\right)_{h}\right)$ matrix of the index eigenvalue $\mathrm{X}$ matrix according to the formula;

4) Calculating the comprehensive relative membership ${ }_{j} U_{h}^{\prime}=\left({ }_{j} u_{h}^{\prime}\right)$ matrix of the safety level $\mathrm{h}$ under the four different combinations of the $\alpha, p$ parameters of the railway crossing and obtain the normalized relative membership degree ${ }_{j} U_{h}=\left({ }_{j} u_{h}\right)$ matrix of the railway crossing safety level.

5) Calculate the safety level eigenvalue vector $H_{j}$ of the railway crossing in the four different combinations of parameters, and calculate the mean value of the level eigenvalue $\bar{H}_{j}$. Finally, the railway crossing safety is evaluated synthetically according to the judgment criterion, and the safety level of the railway crossing is determined.

\section{Case Study}

Through the theory of variable fuzzy sets, the risk management evaluation of the railway crossing safety system at Gaizhou Road, Dali Road, Dalian City is carried out to determine the safety level, so as to improve its safety.

\subsection{Safety Status Indicators Eigenvalues And Levels}

Table 2.Quantitative Table of Safety Status Indicators for the Crossing of the Yellow River Road

$\begin{array}{llll}\text { Target layer } & \text { Index layer } 1 \quad \text { Weights } & \text { Index layer } 2 & \text { Weights }\end{array} \begin{gathered}\text { Index } \\ \text { value }\end{gathered}$

\begin{tabular}{|c|c|c|c|c|c|}
\hline \multirow{12}{*}{$\begin{array}{l}\text { Safety conditions of } \\
\text { railway crossing }\end{array}$} & \multirow{4}{*}{$\begin{array}{l}\text { equipment } \\
\text { factors }\end{array}$} & \multirow{4}{*}{0.51} & Signal safety status & 0.42 & 91 \\
\hline & & & $\begin{array}{l}\text { Crossing position setting } \\
\text { situation }\end{array}$ & 0.23 & 81 \\
\hline & & & Column wood safe state & 0.23 & 88 \\
\hline & & & $\begin{array}{l}\text { Crossing the train close to } \\
\text { early warning time }\end{array}$ & 0.12 & 86 \\
\hline & \multirow{2}{*}{ vehicle factors } & \multirow{2}{*}{0.23} & $\begin{array}{l}\text { Crossing the state of } \\
\text { motor vehicles }\end{array}$ & 0.67 & 73 \\
\hline & & & $\begin{array}{l}\text { Crossing the vehicle } \\
\text { density }\end{array}$ & 0.63 & 79 \\
\hline & \multirow{4}{*}{$\begin{array}{c}\text { crossing } \\
\text { characteristics }\end{array}$} & \multirow{4}{*}{0.12} & Crossing width & 0.32 & 92 \\
\hline & & & Crossing slope & 0.15 & 85 \\
\hline & & & $\begin{array}{l}\text { Crossing the road and the } \\
\text { railway angle }\end{array}$ & 0.07 & 96 \\
\hline & & & $\begin{array}{c}\text { Crossing the road near the } \\
\text { road }\end{array}$ & 0.46 & 91 \\
\hline & \multirow{2}{*}{ personnel factors } & \multirow{2}{*}{0.14} & $\begin{array}{l}\text { The condition of crossing } \\
\text { guardians }\end{array}$ & 0.75 & 91 \\
\hline & & & $\begin{array}{c}\text { Ports security } \\
\text { management file status }\end{array}$ & 0.25 & 85 \\
\hline
\end{tabular}

\subsection{Determination Of Relative Membership Degree Matrix}

According to the above steps, the membership degree matrix is obtained: 


$$
\begin{aligned}
& \mu_{A}^{\circ}(x)=\left(\begin{array}{ccccc}
0.775 & 0.225 & 0 & 0 & 0 \\
0.525 & 0.475 & 0 & 0 & 0 \\
0.7 & 0.3 & 0 & 0 & 0 \\
0.65 & 0.35 & 0 & 0 & 0
\end{array}\right) \mu_{A}^{\circ}(x)=\left(\begin{array}{lllll}
0.227 & 0.651 & 0.122 & 0 & 0 \\
0.432 & 0.545 & 0.023 & 0 & 0
\end{array}\right) \\
& \mu_{A}^{\circ}(x)=\left(\begin{array}{ccccc}
0.8 & 0.2 & 0 & 0 & 0 \\
0.625 & 0.375 & 0 & 0 & 0 \\
0.9 & 0.1 & 0 & 0 & 0 \\
0.775 & 0.225 & 0 & 0 & 0
\end{array}\right) \mu_{A}^{\circ}(x)=\left(\begin{array}{lllll}
0.775 & 0.225 & 0 & 0 & 0 \\
0.625 & 0.375 & 0 & 0 & 0
\end{array}\right)
\end{aligned}
$$

\subsection{Determine The Railway Crossing Safety Level}

According to the weight of the index and the normalized relative membership matrix calculated in Table 3, the sample $\mathrm{j}$ is divided into four groups according to the formula: $\mathrm{h}(\mathrm{h}=1,2,3,4,5)$, and the level eigenvalue of sample $\mathrm{j}$ is obtained by using the level eigenvalue formula.

Table 3. First - level indicators of the four groups of model parameters of the level of eigenvalues

\begin{tabular}{cccccc}
\hline \multirow{2}{*}{ Level 1 evaluation index } & \multirow{2}{*}{$\omega$} & $\alpha=1$ & $\alpha=1$ & $\alpha=2$ & $\alpha=2$ \\
\cline { 3 - 6 } & & $p=1$ & $p=2$ & $p=1$ & $p=2$ \\
\hline equipment factors & 0.51 & 1.3158 & 1.2976 & 1.1742 & 1.1522 \\
vehicle factors & 0.23 & 1.7946 & 1.8365 & 1.8416 & 1.8748 \\
crossing characteristics & 0.12 & 1.2307 & 1.2310 & 1.0826 & 1.0828 \\
personnel factors & 0.14 & 1.2605 & 1.2428 & 1.1124 & 1.0923 \\
\hline
\end{tabular}

According to Table 2-2, the level eigenvalues of the primary index are multiplied by the corresponding weights respectively, that is, the level characteristic values of the road comprehensive security situation are as follows:

$\alpha=1, p=1 \mathrm{~h}, \mathrm{H}_{1}=1.4083, \alpha=1, p=2 \mathrm{~h}, \mathrm{H}_{2}=1.4059$

$\alpha=2, p=1 \mathrm{~h}, \mathrm{H}_{3}=1.3081, \alpha=2, p=2 \mathrm{~h}, \mathrm{H}_{4}=1.3017$

According to the criteria to determine the evaluation results for a level, the Yellow River Road, crossing the security situation for the security.

\subsection{Suggestions on Safety Risk Management of Railway Crossing}

1) Constantly improve the railway crossing the safety of the equipment, timely organization crossing equipment maintenance and replacement, to ensure the normal work of the equipment.

2) In the pedestrian and traffic flow density of the railway crossing to widen the width of the crossing, slow traffic congestion. For the frequent accidents of the railway crossing, as far as possible by the level of change to interchange;

3) to improve the road near the road surface quality, improve the strength of the road, stability, flatness; to the motor vehicle drivers to carry out safety education on the railway crossing to make it aware of the seriousness of the railway crossing accident and understand the various measures to be taken at the railway crossing to improve its safety awareness;

4) on the pedestrian safety publicity and education, causing people's warning, to improve the safety of the railway crossing awareness; through the television, newspapers and other media to promote and post the railway crossing safety related slogans, and constantly improve people's awareness of the safety of the railway crossing;

\section{Summary}

The railway crossing safety system is a complex system, which is the result of the interaction of many factors, including the determinants of equipment factors, crossing factors and other factors, as well as the uncertain factors such as pedestrian and crossing staff. To improve the safety of railway crossing need to cooperate with each other from engineering, education and rule of law to improve the overall safety of railway crossing safety system. The use of variable fuzzy set theory to evaluate the safety risk management of railway crossing, can solve the problem of uncertainty and fuzziness 
of various factors in complex system, and overcome the applicability of the maximum membership principle under fuzzy concept classification.

\section{References}

[1]. Tang Baojun, Zhou Baojin, Zhang Kun. Analysis of influencing factors of energy consumption in Beijing and its energy saving and emission reduction research - Based on social and private traffic perspective [J]. China Energy, 2016, (08): 25-32.

[2]. Zhao Xue-feng. Study on Method of Safety Risk Management in Station [J]. Operations Research and Management Science, 2014, 36 (03): 60-64.

[3]. Deng Han. Based on the property mathematics of the railway crossing crossing safety evaluation and application [D]. Dalian Jiaotong University, 2012.

[4]. LV Feng. Discussion on Countermeasures of Railway Safety Risk Management [J]. Operations Research and Management Science, 2014, 36 (12): 38. 